\title{
Benchmarking Of Johannesburg Stock Exchange CEO Compensation
}

Merwe Oberholzer, North-West University, Potchefstroom, South Africa Marli Theunissen, North-West University, Potchefstroom, South Africa

\begin{abstract}
The purpose of the study is to empirically compare CEO compensation benchmarks set by the frequently used Linear Regression Analysis (LRA), which is based on "averages" and Data Envelopment Analysis (DEA), which is based on "best practices". To fulfill this purpose, an empirical investigation on South African listed companies was executed using a sample of 187 Johannesburg Stock Exchange (JSE) companies, grouped into three categories according to their sizes by using total assets, i.e. large, medium and small companies. For the LRA model, total CEO compensation is the dependent variable (y) with return on equity (as a measurement of performance) and total assets (as measurement of company size) as the independent variables ( $x$ ). In the LRA model, the expected CEO compensation was calculated as a benchmark for each company and then compared to the actual value of the CEO compensation. In the DEA model, total CEO compensation is the input variable and return on equity and total assets the two output variables. The input-orientated technical efficiency estimate was calculated and the input targets (benchmarks for CEO compensation) set by the DEA model were compared to the actual CEO compensation. The study found that, using the LRA model, CEOs are on average actually underpaid in monetary terms by $36.8 \%, 33.2 \%$ and $17.8 \%$ for the large, medium and small companies, respectively. In contrast, the results for these three groups using DEA have shown that CEOs are on average actually overpaid in monetary terms by $47.6 \% 55.3 \%$ and $49.9 \%$. This implies that LRA favors CEOs in comparison with the DEA model. Therefore, the study concludes that the frequently used LRA model is probably a reason that contributes to excessive CEO compensation.
\end{abstract}

Keywords: CEO Compensation; CEO Remuneration; Data Envelopment Analysis; Linear Regression Analysis; Technical Efficiency

\section{INTRODUCTION}

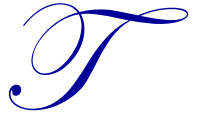

his paper is an empirical investigation of two alternative models to analyze CEO compensation with special reference to South Africa. The logic of the study follows a route of statistical modeling, i.e. that Data Envelopment Analysis (DEA) is investigated as an alternative to the frequently used Linear Regression Analysis (LRA) to predict benchmark CEO compensation. The interest in this topic is that excessive CEO compensation is seen as pay hikes by many stakeholders. Since stock markets are sensitive to CEO information (Bernard, 2008; Setiawan, 2008), the CEO's remuneration should send the appropriate signal to stakeholders (Theunissen, 2010). Companies signal that their CEO is above average and therefore these excessive compensations are in a continuously increasing upwards spiral due to most company boards wanting their CEO to be in the top half of the CEO's peer group (Hayes \& Schaefer, 2007). In this regard, Banks (2009) reported that the discrepancy between pay and performance is suspicious and communities are concerned that CEO compensation is out of control. Examples regarding these concerns are that CEOs reap the benefits of an increased share price when they exercise their share options, while the increase was probably due to market factors and not so much to their own performance, and secondly, that the gap between CEO salaries and the average wage of an ordinary worker is continuously increasing (Joubert, 2011; SAPA, 2011). Furthermore, governments are also concerned with excessive CEO remuneration (Financial Mail, 2008; Ensor, 2010; The Associated Press \& McClatchy Newspapers, 2009) which is described as a cancer that is the core of economic ills (Hindery, 2008). 
CEO compensation data is readily available in South Africa since all public companies are obligated to disclose these figures. As a result, Adcorps' new quarterly Labour Market Navigator analyzed 212 JSE Security Exchange-listed companies by using LRA, and published their results, including by how much each company's CEO is over- or underpaid (Finweek, 2012). The importance of this study is that LRA, as a model to set a benchmark for CEO compensation, is challenged and compared with DEA. The difference between the benchmarks set by the two models will help to better understand the benchmarking of CEO compensation, which can assist board members to set fair CEO packages on behalf of the shareholders. Other interested stakeholders are employees, governments and the broader society, which are calling for fairness.

Up until now, researchers mainly used LRA, a two-dimensional statistical model, to analyze CEO compensation. These studies investigated the relationship between CEO compensation and company determinants such as performance and size (Bradley, 2011; Dommisse, 2011; Theunissen, 2010; Chen et al., 2008; Nourayi \& Daroca, 2008; Barber et al., 2006; Krugel \& Kruger, 2006). LRA is used as a parametric method to benchmark CEO compensation by finding a straight-line equation between numeric random variables (Wegner, 2007), e.g. where independent variables such as company size and performance are used to estimate (or set a benchmark) what the CEO compensation should be. The problem is that this benchmark is based on an "average" set by the companies that are studied in a sample (Thanassoulis, 1993). What is needed is a model to rather set a benchmark that is based on best practice. DEA can help in this regard, since it is a linear programming method to construct a non-parametric surface over the data (Coelli et al., 2005). Multiple inputs (e.g. different components of CEO remuneration) and multiple outputs (e.g. variety of size and performance indicators) are included to estimate the "best practice" frontier by finding a set of linear segments that envelop the observed data (Cook \& Seinford, 2008). Opposed to LRA, where many similar studies were found, only one study, by Cordeiro et al. (2006), was detected that used DEA as a nonparametric method to benchmark CEO compensation. The central argument of this study is that DEA should be considered as a CEO compensation benchmarking model since its benchmark is based on "best practices", where LRA is only based on "averages". The main focus of this study will be to investigate DEA as an alternative model to benchmark CEO compensation. The missing knowledge in the literature is that it is uncertain how the benchmarks of LRA differ from the benchmarks of DEA.

Therefore, the purpose of the study is to empirically compare the results of CEO compensation benchmarks set by LRA and DEA. To fulfill this purpose, a literature study was firstly done to investigate LRA and DEA as benchmarking models. Secondly, an empirical investigation on South African listed companies was executed using a sample of 187 listed JSE companies. Hereupon, it is hypothesized that the benchmark mean (average) of LRA is greater than the benchmark mean (average) of DEA (input targets). Cross-sectional data of CEO compensation and company determinants were obtained from the McGregor BFA (2012) database for the 2010 financial year. The study found that, using the LRA model, CEOs are on average actually underpaid whereas the CEOs are actually overpaid according to the DEA model. The contribution thereof is that this extends the current literature by indicating how extremely different the results of the two models are.

The rest of the paper is organized as follows: The next section provides a background to the study, followed by a section that explains the theory of the two models and a section that explains the research design and methodology. This is followed by a section that reveals the findings and the study is summarized and concluded in the final section.

\section{BACKGROUND}

\section{Relevance of the study}

The relevance of this study is explained by discussing the concerns shareholders and other stakeholders have regarding excessive CEO compensation. Excessive CEO compensation has detrimental effects on businesses as well since the total cost of overpayment could in some cases significantly affect shareholder returns. Stakeholders, other than shareholders, are also affected by excessive compensation; for example, it affects employment turnover, since employees regard CEO remuneration as a beacon to determine the fairness of their own salaries. It is more likely for employees to resign if their CEO is significantly overpaid (Amble, 2006; Wade et al., 2006). The attention that CEO compensation gets is a result of the gap between CEO salaries and the average wage of an ordinary worker 
which is continuously increasing. A good example is the recent wage strikes (2011) in South Africa. Salaries of executives from the Top 40 JSE companies increased by 23\%, while their short-term incentives increased by 56\% over the past year. At the same time, the National Union of Metalworkers of South Africa (NUMSA) was struggling to get a 13\% raise on their workers' meager salaries (Joubert, 2011). The Congress of South African Trade Unions (COSATU) claims that huge pay hikes of top executives are unacceptable while workers fight for reasonable wages (SAPA, 2011).

In the media, much attention is given with regard to the relationship between CEO compensation and company performance. All agreed that CEO remuneration is excessively high and could be linked to the global financial crisis. For example, a report by the Australian Productivity Commission stated that large payments, despite poor company performance, have fuelled community concerns that executive remuneration is out of control (Banks, 2009). Former South African finance minister, Trevor Manuel, reported that government is concerned as ever about pay levels, especially where there is no relation to the performance of the company (Financial Mail, 2008). Current finance minister, Pravin Gordhan, shares this view by saying that extreme earnings disparities cause offence not just when they are associated with profiteering or financial malfeasance, but also when the reward for honest work seems disproportionate or weakly aligned with incentives (Ensor, 2010). Furthermore, German chancellor Angela Merkel is researching ways to curb excessive executive pay that aroused from long-term incentive schemes such as share options. Recent investigations revealed that CEOs made millions when they exercised their share options (Financial Mail, 2008). The size of the gain mainly depends on the number of share options and the prevailing share price on the date the option is exercised. To a certain extent, a CEO can influence the share price through good governance, but there are also uncontrollable market factors that can influence the share price. This fuels the argument that CEOs reap the benefits of an increased share price while the increase was due to market factors and not so much to their own contribution.

\section{Literature review}

The previous studies will serve as a basis to develop LRA and DEA models to predict CEO compensation benchmarks. The rest of this paragraph is a summary of studies that used LRA as a model to estimate CEO compensation. Bradley (2011) studied the largest 40 JSE companies (in terms of market capitalization), broken up into mining-, financial services- and industrial sectors over a five-year period and found that there is no linear relationship between CEO compensation and company performance variables; however, the study found correlations between age and experience and CEO compensation. Dommisse's (2011) study included the top 120 companies on the JSE (according to market capitalization) at the end of 2009. A correlation between total CEO remuneration, including all cash and share rewards, was brought in relation with turnover, total income and earnings before interest and tax (EBIT). It was found that more than $80 \%$ of all correlation observations resulted in a positive correlation meaning that CEO remuneration only increased when there was an increase in turnover, income and EBIT. Therefore, CEO remuneration of the vast majority of JSE-listed companies demonstrates a strong correlation with the company's financial achievements. Theunissen (2010) analyzed 326 companies, which included JSE-listed companies and state-owned companies. The linear relationship between total CEO remuneration and several business factors such as turnover, turnover growth, total assets, total equity and profit was analyzed. The study found that no single business factor emerged as the main determinant of CEO remuneration. Nourayi and Daroca (2008) studied 455 US firms from 25 industries from 1996 to 2002. They found that firm size and market-based returns are the most significant explanatory variables affecting CEO compensation and more limited support was found for accounting-based returns and changes in the number of employees. Krugel and Kruger (2006) included all the JSE-listed companies in their study, except companies with foreign CEOs or foreign companies listed on the JSE. No direct relationship between company profits and CEO remuneration was found. A separate comparison for each of the remuneration elements, namely salaries, bonuses and total remuneration was made to company profits for the current and previous year, respectively. Barber et al. (2006) investigated the restaurant industry and found a weak, but positive, relationship between CEO compensation and gross revenue and net income and a significant positive relationship with stock prices. Chen et al. (2008) is another study that used LRA to benchmark the CEO compensation for the top 20 US banks on an annual basis from 1997 to 2004. One of the independent variables in their formula was the DEA score to determine the performance (efficiency) to convert six inputs (CEO compensation, non-interest expenses, total assets, total deposits, number of branches and number of employees) into two outputs (revenue and net income). The other independent variable is expenses as a proxy for the firm size. This 
study found that the DEA score is a highly significant predictor of CEO compensation and that the efficient banks (DEA score of 1) rewarded CEOs with a higher compensation than inefficient banks. To summarize, these studies used a variety of company determinants to measure company performance, using accounting-based and marketbased measures, and various measures as proxies for company size. Some of the results in these previous studies indicate that there is no relationship between CEO remuneration and company size and/or performance measures, while others indicated strong and statistically significant positive relationships with some of the performance/size measures. Nevertheless, no specific pattern can be identified from these studies.

Only one study was found that used only DEA to investigate CEO compensation, i.e. Cordeiro et al. (2006), which used total CEO compensation (an aggregation including cash salary, bonus and stock-derived compensation) as input variable and firm size (in terms of sales) and company performance (in terms of return on assets, net profit margin and stock return) as output variables.

\section{Conceptual scope and context of the study}

Against this backdrop of the critics on excessive CEO compensation, the conceptual scope of the study is that CEO compensation should be fair in relation to what the CEO is worth to a company. The Longman Dictionary (2004) uses the word reasonable and acceptable as synonyms for "fair". It further explains it as "a fair situation, system, way of treating people, or judgment seems to be reasonable, acceptable, and right...". Therefore, the compensation should be earned, which implies there should be a relationship between CEO compensation and the company size and company performance.

The current focus can be explained in the words of Mark Bussin, chairman of 21st Century Pay Solutions, who explains the complexity of this issue by asking 'a tricky question': "How do you judge if someone is overpaid?" (Financial Mail, 2008). This question can also be extended by asking the opposite, namely to judge underpaying. Therefore, the open question of this study is whether LRA is the most appropriate model to set a benchmark for CEO compensation that is fair, in other words that over- or under compensations can be avoided. Furthermore, should DEA be used as an alternative model? And finally, what are the differences in CEO compensation benchmarks by using the two alternative models?

\section{THEORY}

\section{LRA as a method to benchmark CEO compensation}

The linear association method embraces regression and correlation analysis, which is widely used to define the structural relationship between variables and the strength of this identified association. Since LRA is widely used and many researchers are familiar with it, it will be discussed only briefly. Simple LRA is a parametric method, indicating on a two-dimensional statistical model only the linear relationship and correlation between two factors, a dependent (y) and an independent ( $\mathrm{x}$ ) variable. Multi-LRA assumes that more than one independent variable influences the outcome of y (Wegner, 2007). The regression line is the estimated value, which is a straight-line that "best" describes, or is most representative of all the data points. For this reason, the straight-line displays the average of all data with data points both beneath of above it.

In this study, the linear association between CEO compensation (y) and company determinants, measuring performance $\left(\mathrm{x}_{1}\right)$ and size $\left(\mathrm{x}_{2}\right)$, will be investigated. Researchers using LRA models can apply a trial and error approach, using as many as possible size indicators (e.g. turnover, total assets, total expenses, number of employees, etc.) and performance indicators (e.g. return on equity, return on assets, price/earnings ratio, price-book value ratio, etc.) to try to detect which of these indicators should be used to estimate CEO compensation. When researchers find a significant relationship (or even no relationship) between CEO compensation and some of these indicators, a contribution is made to the literature because it is empirically proved that, for a sample group of companies, a change in such an indicator leads (does not lead) to a change in CEO compensation. With this knowledge, a company's board has coefficients to use in order to estimate their CEO's compensation. 


\section{DEA methodology}

DEA is a non-parametric linear programming technique that measures the relative efficiency of a comparative ratio of outputs to inputs for a particular decision-making unit (DMU) (Ray, 2004). DEA is a relative efficiency measure that accommodates multiple inputs, multiple outputs and other factors in a single model (Halkos \& Salamouris, 2004). Furthermore, it provides the ability to identify inefficient organizations and potential improvement areas for these organizations, as well as highlighting efficient organizations that could be used as benchmarks by less efficient organizations (Avkiran, 1999). The fundamental assumption of DEA is that if a producer (DMU) is capable of producing $Y(\mathrm{~A})$ units of output with $X(\mathrm{~A})$ inputs, then other producers should also be able to do the same if they were operating efficiently. The fundamental objective of the DEA modeling exercise is to find the "best" virtual producer for each real producer and then to compare the producer to its best virtual producer in order to determine its efficiency. The best virtual producer is found by means of linear programming (Anderson, 1996).

The focus of this study is on estimating technical efficiency, which is an indication of how well inputs are converted into outputs (Avkiran, 1999; Coelli et al., 2005). In other words, how well did a CEO perform, with his/her compensation as input, in relation with company determinants, such as performance and size. Analysts typically choose between using constant return to scale (CRS) or variable return to scale (VRS) (Buys et al., 2011). The CRS implies a proportionate rise in outputs when inputs are increased, or in other words, an organization's efficiency is not influenced by the scale of its operations (Avkiran, 1999). This is a significant assumption, since CRS may only be valid over a limited range and its use should be justified (Anderson, 1996). Furthermore, Avkiran (1999) states that VRS implies a disproportionate rise or fall in outputs when inputs are increased, or in other words, if an organization grows in size, its efficiency will not remain constant, but it will either rise or fall.

Analyzing the efficiency of a number of DMUs requires a formulation of a linear programming problem for each DMU. "lambda is a vector describing the percentage of other producers used to construct the virtual producer. lambda $X$ and lambda $Y$ are the input and output vectors for the analyzed producer. Therefore, $X$ and $Y$ describe the virtual inputs and outputs, respectively" (Anderson, 1996). Theta $(\theta)$ indicates the producer's efficiency. The following is the DEA input-orientated primal formulation (Anderson, 1996):

$\min \theta$,

s.t. $\gamma \lambda \geq \gamma_{0}$,

$\theta \chi_{0}-\chi \geq 0$,

$\theta$ free, $\geq 0$.

DEA will be explained by a single input two-output, constant return to scale problem, because it is easy to analyze graphically. The data is given in Table 1 where CEO compensation is the input variable and assets and profit the company determinants representing size and performance, respectively.

Table 1: Single Input, Two-output Example

\begin{tabular}{|l|c|c|c|}
\hline \multirow{2}{*}{ Firm } & Input & \multicolumn{2}{c|}{ Output } \\
\cline { 2 - 4 } & CEO compensation (Rm)* & Assets (Rm) & Profit (Rm) \\
\hline A & 10 & 120 & 5 \\
B & 10 & 110 & 20 \\
C & 10 & 105 & 20 \\
D & 10 & 100 & 20 \\
\hline
\end{tabular}

* R = Rand, the South African currency, ZAR

Figure 1 visually exhibits the data in Table 1. The line connecting Companies A and $\mathrm{C}$ show the possibilities of virtual outputs that can be formed by them. Company A is fully efficient having assets, since no combination of B, C and D has assets of R120m with the constraint of only R10m CEO compensation. Firm C and 
Firm D are fully efficient to generate profit, since no combination of A and B can earn profit of R20m with the constraint of only R10m of CEO compensation.

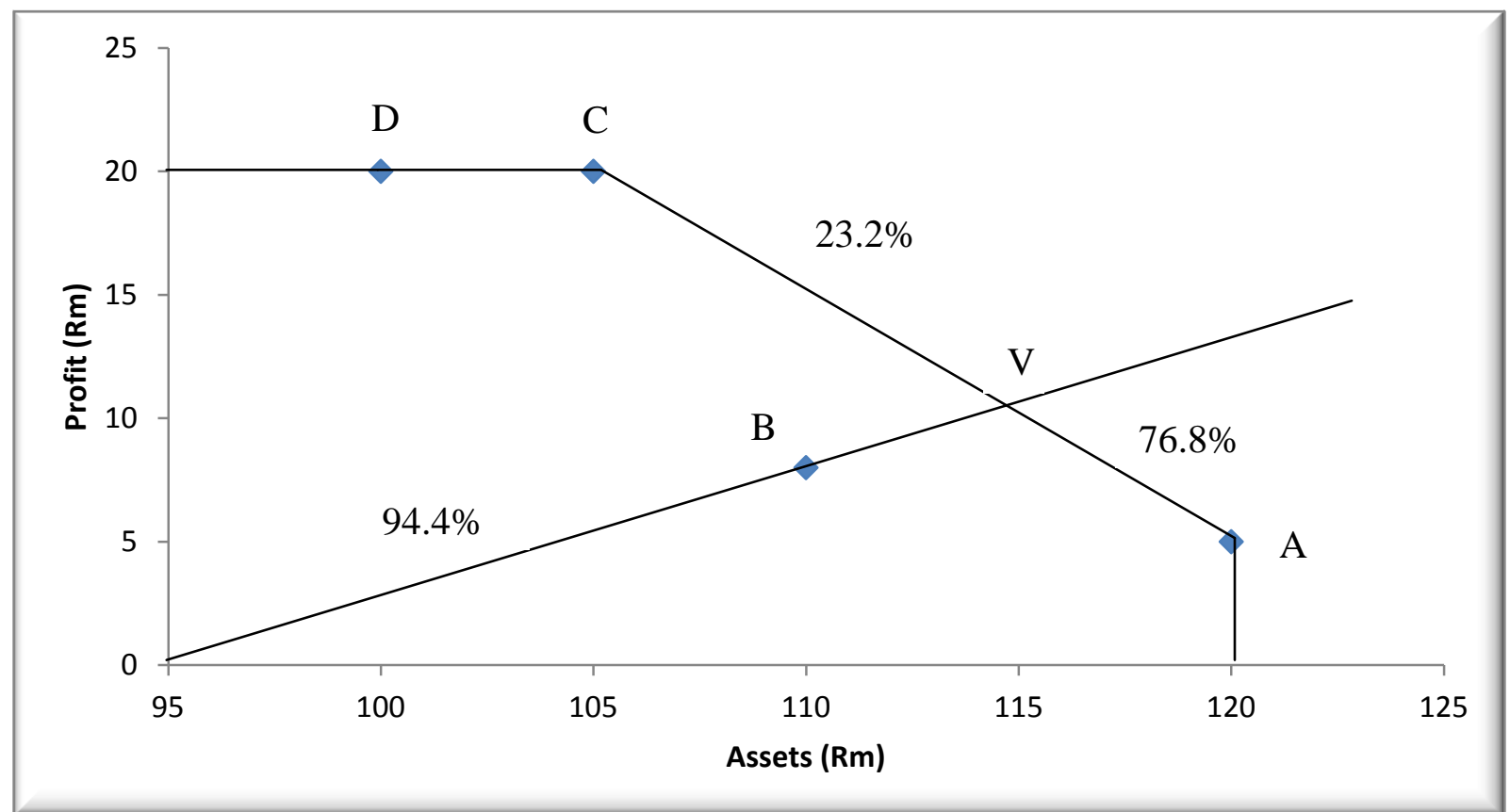

Figure 1: DEA example

In Figure 1, the line $\mathrm{CA}$ lies beyond $\mathrm{CB}$ or $\mathrm{BA}$, which means that $\mathrm{CA}$ is the efficiency frontier where any combination of $\mathrm{A}$ and $\mathrm{C}$ will create the highest output for the given input. Firm $\mathrm{B}$ is below the efficiency frontier and therefore it is inefficient. The efficiency of B can be determined by its virtual firm (V) formed by Firms A and C. The virtual firm, which is the benchmark for B, is $76.8 \%$ of $\mathrm{A}(1-\mathrm{AV} / \mathrm{AC})$ and $23.2 \%$ of $\mathrm{C}(1-\mathrm{VC} / \mathrm{AC})$. This means that lambda $=[0.768,0.232]$. The virtual vector output is now:

$\lambda Y=[0.768 \times 120+0.232 \times 105,0.768 \times 5+0.232 \times 20]=[116.5,8.5]$

From an input-orientated view, the efficiency of $\mathrm{B}$ is the fraction of inputs that $\mathrm{V}$ would need (that is $0 \mathrm{~B}=$ 94.4 percent of $0 \mathrm{~V}$ ) to produce the same output as B. Firm D is also on the efficiency frontier, but DC indicates a slack. That means D should move to point $\mathrm{C}$.

\section{Comparison between LRA and DEA}

The advantages of DEA over LRA and the advantages of LRA over DEA are exhibited in Table 2. This is taken from Thanassoulis (1993) who has done a complete study in this regard. However, the main focus of this study is that LRA offers the facility to test assumptions about mathematical relationships assumed between input and output variables, which describe a regression line that indicates an average over the data. In contrast, DEA measures performance against efficiency rather than average performance. 
Table 2: Advantages of DEA and LRA over each other

\begin{tabular}{|c|}
\hline SEA over LRA \\
\hline 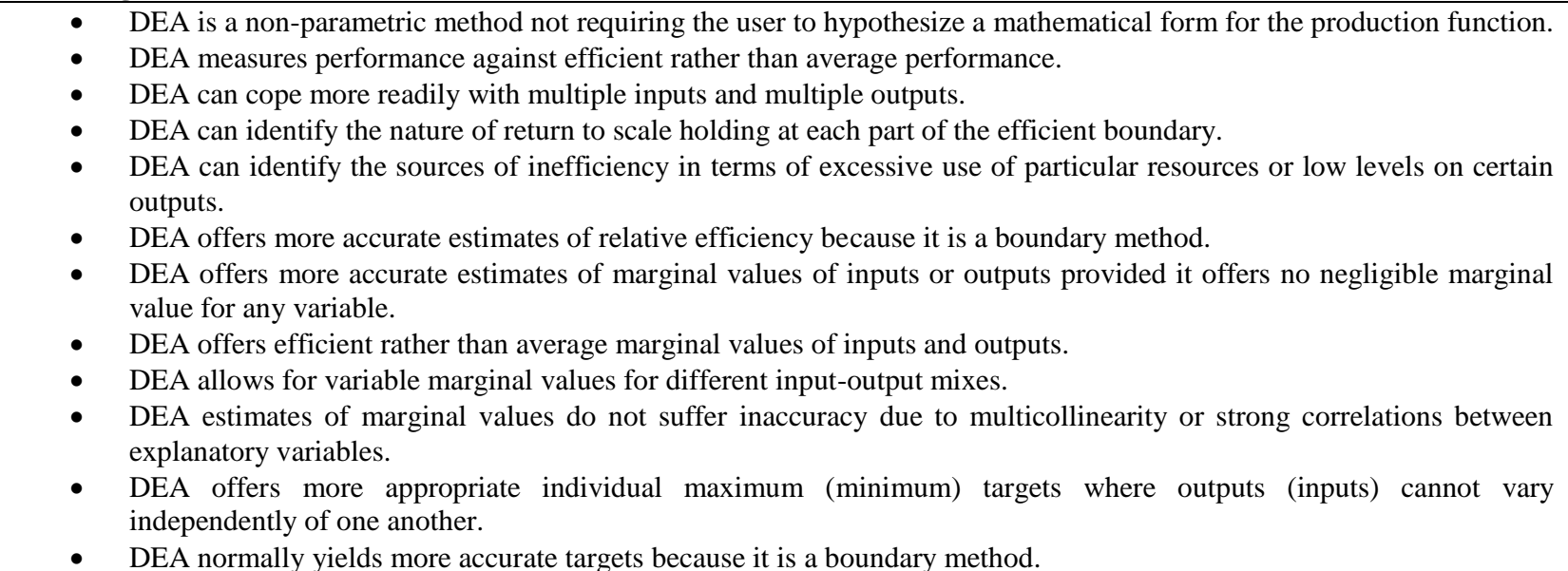 \\
\hline Advantages of LRA over DEA \\
\hline $\begin{array}{l}\text { - LRA offers a better predictor of future performance at the collective DMU level if it is assumed inefficiencies cannot } \\
\text { be eliminated. } \\
\text { - LRA offers the facility to estimate confidence intervals for point estimates. } \\
\text { LRA offers the facility to test assumptions about mathematical relationships assumed between input and output } \\
\text { variables. } \\
\text { LRA normally offers more stable accuracy of estimates of relative efficiency and target input-output levels because the } \\
\text { estimates are not dependent on only a small subset of observed input-output levels. } \\
\text { LRA estimates the marginal input-output values and relative efficiency are more transparent and can be more readily } \\
\text { communicated to the lay person. } \\
\text { LRA could yield better estimates of individual maximum (minimum) levels where outputs (inputs) vary independently } \\
\text { of one another. }\end{array}$ \\
\hline
\end{tabular}

Source: Thanassoulis, 1993

\section{METHOD}

\section{Sample and data}

To fulfill the purpose of the study, i.e. to empirically compare the results of CEO compensation benchmarks set by LRA and DEA, an empirical investigation on South African listed companies is executed. In total, data for 359 companies, listed on the Main Board of the JSE, were obtained from the McGregor BFA (2012) database. Unfortunately, the data of 138 companies could not be used since the majority of this group does not provide CEO compensation data, while the remaining companies seem to not be operational anymore and are probably already delisted or in a process of delisting. The fact that this is a convenient sample, since only readily available data are used and unavailable data are excluded (Maree, 2011), may not be a problem, because this study does not want to make deductions to generalize to all the listed companies. In other words, the study does not aim to set a benchmark CEO compensation value to each JSE-listed company. Therefore, the aim is rather to do an exploratory study to get an idea of the differences in the benchmarking results when LRA and DEA are used as alternative models to set a benchmark regarding to CEO compensation.

Cross-sectional data of CEO compensation and company determinants were obtained for the 2010 financial year. Since companies use different year-end dates, all the monetary values were adjusted to 31 December 2010 by using the Production Price Index (PPI) (Statistics SA, 2012). Few companies report in foreign currencies (USD, AUD, CAD, GBP and EUR). These values were converted to ZAR by using the average exchange rate for 2010 . The companies were grouped into three categories according to their sizes using total assets, i.e. large (75), medium (76) and small (70) companies. After visual inspection of the data, it was decided to exclude the 15 largest companies, because their asset values are extremely high compared to the remaining companies. The method used to 
deal with outliers in all the variables is to omit data values that lie more than 1.5(Quartile ${ }_{3}-$ Quartile $_{1}$ ) away from either the lower quartile or the upper quartile (Wegner, 2007). This results in category sizes of $n=55, n=64$ and $n=68$ for the large, medium and small companies, respectively. This means that, in total, 187 companies were analyzed.

\section{Variables and models}

As this is an exploratory study, the company determinants are quite simple and the same determinants are used in both models. Profitability, which is the stepping-stone in creating shareholders' value, gets substance in ratios, for example the ratios included in the Du Pont formula have the strength to aggregate the firm's performance in three broad categories, namely income, investments and capital structure (Correia et al., 2011). Return on equity (ROE) is a comprehensive company performance indicator including the three broad categories, since it aggregates how the net profit margin and asset turnover affect return on assets, and how return on assets and leverage affect return on equity (Asaftei, 2008). Therefore, the first company performance determinant used in this study is return on equity.

The second company determinant is total assets, which is an indication of size. Studies such as Chen et al. (2008) and Theunissen, (2010) also used total assets as a company determinant, while Chen et al. (2008) also used expenses, Cordeiro et al. (2006) used sales, and Nourayi and Daroca (2008) used the number of employees as a proxy for firm size. Again, the aim is not to debate which is the most superior variable to use, but rather to determine how it influences the results among the two alternative models.

CEO compensation is the total compensation in 2010 as reported by McGregor BFA (2012), i.e. a fixed short-term pay in the form of a salary and benefits, fixed long-term pay in the form of a pension, variable short-term pay in the form of an annual bonus and variable long-term pay in the form of a deferred bonus and long-term incentive awards.

For the LRA model, multiple linear regression analysis was used for each of the three samples. The equation is (Wegner, 2007; Swanepoel et al., 2010):

$\mathrm{y}=\mathrm{b}_{0}+\mathrm{b}_{1} \mathrm{x}_{1}+\mathrm{b}_{2} \mathrm{x}_{2}+\varepsilon$

Where

$\mathrm{y}=$ dependent variable, $\mathrm{CEO}$ compensation (in terms of ZAR)

$\mathrm{b}_{0}=$ intercept

$\mathrm{b}_{1}=$ slope of $\mathrm{y}$ with variable $\mathrm{x}_{1}$ holding variable $\mathrm{x}_{2}$ constant

$\mathrm{b}_{2}=$ slope of $\mathrm{y}$ with variable $\mathrm{x}_{2}$ holding variable $\mathrm{x}_{1}$ constant

$\mathrm{x}_{1}=$ independent variable, return on equity

$\mathrm{x}_{2}=$ independent variable, total assets (in terms of ZAR)

$\varepsilon=$ Random error in $\mathrm{y}$

The "expected" or "average" CEO compensation is calculated, as a benchmark, regarding each company and compared to the actual value of the CEO compensation. The equation is (Wegner, 2007):

$\hat{y}=b_{0}+b_{1} x_{1}+b_{2} x_{2}+\varepsilon$

Where $\hat{y}=$ the expected value of the dependent variable

Furthermore, an efficiency estimate is calculated by dividing the expected (benchmark) CEO compensation (y) into the actual CEO compensation (y).

In the DEA model, the input and output variables are:

Input: $\mathrm{x}_{1}=\mathrm{CEO}$ compensation (in terms of ZAR) 
Output: $\mathrm{y}_{1}=$ return on equity

$\mathrm{y}_{2}=$ total assets (in terms of ZAR)

The software developed by Zhu (2004) was used to calculate the input-orientated technical efficiency estimates, using the less restricted variable return to scale (VRS), to determine how efficient each company's CEO is relatively to convert his/her compensation into the company determinants of return on equity and total assets. Furthermore, the input targets (benchmarks for CEO compensation) set by the DEA model are compared to the actual CEO compensation.

\section{Hypothesis}

Since it is clear that the benchmark CEO compensation according to the LRA model ( $\hat{y})$ is based on averages, while it is based on best practices according to the DEA (input targets), the expectation is that the differences between $\hat{y}$ and the input targets for the three groups of companies are significant. A one-sided uppertailed test will be performed to show that the benchmark mean (average) of $\hat{y}$ is greater than the benchmark mean (average) of the input targets.

Therefore, the (main) null and alternative hypotheses of this study, testing for differences between the sample means are:

$$
\begin{array}{ll}
\mathbf{H}_{\mathbf{0}} & =\mu_{\mathrm{LRA}}-\mu_{\mathrm{DEA}}=0 \\
\mathbf{H}_{\mathbf{1}} & =\mu_{\mathrm{LRA}}-\mu_{\mathrm{DEA}}>0
\end{array}
$$

\section{FINDINGS}

To ensure that the data are suitable for Multi-LRA, descriptive statistics were evaluated together with a visual inspection of the data. Linearity, normality and heteroskedasticity seem to be in order and there is no multicollinearity since the correlation coefficients between $\mathrm{x}_{1}$ and $\mathrm{x}_{2}$ are low, i.e. $0.203,0.042$ and -0.197 for large, medium and small companies, respectively. Furthermore, a null and alternative hypothesis test (secondary to the main hypothesis of the study) was conducted on the regression coefficients. The multiple regression model is of no value in estimating y when the population regression coefficients $\left(\beta_{1}\right.$ and $\left.\beta_{2}\right)$ are both zero, but there is value in the regression line when at least one regression coefficient is not zero (Wegner, 2007). Therefore,

$$
\begin{array}{ll}
\mathbf{H}_{\mathbf{0}}: & \beta_{1}=\beta_{2}=0 \\
\mathbf{H}_{\mathbf{1}}: & \text { At least one } \beta \neq 0
\end{array}
$$

Table 3 exhibits firstly a summary of the descriptive statistics of y, CEO compensation, for large, medium and small companies, respectively. Furthermore, from the regression and correlation analysis, it is clear from $\mathrm{R}^{2}(\mathrm{R}$ Square) that variations in $\mathrm{x}_{1}$ and $\mathrm{x}_{2}$ explain $10.0 \%, 14.7 \%$ and $35.2 \%$ in the variation in CEO compensation, $\mathrm{y}$. According to Ellis and Steyn (2003), $R^{2}$ is non-significant for large companies $\left(R^{2}<0.13\right)$, while $R^{2}$ is significant with regard to medium companies $\left(0.13<\mathrm{R}^{2}>0.25\right)$ and practically important for small companies $\left(\mathrm{R}^{2}>0.25\right)$. Furthermore, all the p-values of the independent variables are significant at 0.05 or 0.10 (two-tailed), which implies that $\mathrm{H}_{0}$ is rejected in favor of $\mathrm{H}_{1}$, i.e. there is value in the regression lines, except for large companies, where the pvalue of 0.567 lies well above 0.1 , implying there is no sample evidence to support the alternative hypothesis, $\mathrm{H}_{1}$. Therefore, when calculating $\hat{y}$ for large companies, return on equity, $x_{1}$, was omitted. The results of $\hat{y}$ and the LRA efficiency values are indicated in Table 4. 
Table 3: Descriptive statistics and regression and correlation analysis

\begin{tabular}{|c|c|c|c|c|}
\hline \multicolumn{5}{|c|}{ Descriptive statistics of y (CEO compensation) (ZAR) } \\
\hline & Large & Medium & Small & \\
\hline Mean & 10794016 & 5316826 & 2790773 & \\
\hline Median & 9793040 & 4603508 & 2569171 & \\
\hline Minimum & 2480000 & 582780 & 567820 & \\
\hline Maximum & 24885036 & 12884000 & 6269112 & \\
\hline \multicolumn{5}{|c|}{ Regression and correlation analysis } \\
\hline & Large & Medium & Small & \\
\hline Multiple R & 0.317 & 0.384 & 0.593 & \\
\hline R Square & 0.100 & 0.147 & 0.352 & \\
\hline Adjusted R Square & 0.066 & 0.119 & 0.332 & \\
\hline Observations & 55 & 64 & 68 & \\
\hline Large & Coefficients & Standard error & $t$ stat & $P$-value \\
\hline Intercept & 9233433 & 1877747 & 4.917 & $<0.001$ \\
\hline $\mathrm{x}=\mathrm{ROE}$ & -4249825 & 7379088 & -0.576 & 0.567 \\
\hline $\mathrm{x}=$ Total assets & 0.081 & 0.037 & 2.179 & 0.034 \\
\hline \multicolumn{5}{|l|}{ Medium } \\
\hline Intercept & 2729240 & 863406 & 3.161 & 0.002 \\
\hline $\mathrm{x}=\mathrm{ROE}$ & 8059026 & 3946009 & 2.042 & 0.045 \\
\hline $\mathrm{x}=$ Total assets & 0.364 & 0.149 & 2.437 & 0.018 \\
\hline \multicolumn{5}{|l|}{ Small } \\
\hline Intercept & 1105786 & 319265 & 3.464 & 0.001 \\
\hline $\mathrm{x}=\mathrm{ROE}$ & 2818433 & 1528125 & 1.844 & 0.070 \\
\hline $\mathrm{x}=$ Total assets & 2.241 & 0.435 & 5.152 & $<0.001$ \\
\hline
\end{tabular}

As a result of space restriction, Table 4 exhibits y as the actual CEO compensation and $\hat{y}$ as the benchmark compensation only for the 55 large companies. Only the average, minimum and maximum values are exhibited for medium and small companies. Furthermore, the LRA efficiency, $\hat{y} / y$, is a standardized indication of the benchmark CEO compensation, relative to the actual CEO compensation, e.g. the positive LRA efficiency value of Company 1 , 1.581 , indicates that this company is relatively efficient, because this company's CEO compensation is less than the benchmark (expected average). The average LRA efficiencies are 1.368, 1.332 and 1.178 for large, medium and small companies, respectively.

Table 4 LRA and DEA efficiencies and benchmarks

\begin{tabular}{|c|c|c|c|c|c|c|c|c|}
\hline \multirow[b]{2}{*}{ Large } & \multirow[b]{2}{*}{$\mathbf{y}$} & \multicolumn{2}{|c|}{ LRA } & \multicolumn{2}{|c|}{ DEA } & \multicolumn{3}{|c|}{ Over- (under)paid \% } \\
\hline & & $\begin{array}{c}\hat{\mathbf{y}} \\
\text { benchmark }\end{array}$ & Efficiency & $\begin{array}{l}\text { Input target } \\
\text { benchmark }\end{array}$ & Efficiency & LRA & DEA & Total \\
\hline 1 & $10,111,000$ & $15,984,851$ & 1.581 & $10,111,000$ & 1.000 & -0.581 & 0.000 & 0.581 \\
\hline 2 & $19,507,000$ & $15,019,144$ & 0.770 & $8,306,487$ & 0.426 & 0.230 & 0.574 & 0.344 \\
\hline 3 & $22,424,000$ & $14,279,131$ & 0.637 & $6,923,705$ & 0.309 & 0.363 & 0.691 & 0.328 \\
\hline 4 & $13,968,963$ & $14,177,121$ & 1.015 & $6,744,630$ & 0.483 & -0.015 & 0.517 & 0.532 \\
\hline 5 & $8,995,000$ & $14,142,382$ & 1.572 & $8,688,504$ & 0.966 & -0.572 & 0.034 & 0.606 \\
\hline 6 & $6,462,701$ & $14,032,419$ & 2.171 & $6,462,701$ & 1.000 & -1.171 & 0.000 & 1.171 \\
\hline 7 & $16,114,750$ & $13,852,475$ & 0.860 & $6,169,789$ & 0.383 & 0.140 & 0.617 & 0.477 \\
\hline 8 & $16,114,750$ & $13,852,475$ & 0.860 & $6,169,789$ & 0.383 & 0.140 & 0.617 & 0.477 \\
\hline 9 & $13,501,174$ & $13,751,262$ & 1.019 & $6,123,777$ & 0.454 & -0.019 & 0.546 & 0.565 \\
\hline 10 & $9,994,223$ & $13,030,460$ & 1.304 & $4,831,719$ & 0.483 & -0.304 & 0.517 & 0.820 \\
\hline 11 & $10,751,708$ & $12,826,877$ & 1.193 & $9,077,886$ & 0.844 & -0.193 & 0.156 & 0.349 \\
\hline 12 & $15,829,731$ & $12,714,928$ & 0.803 & $9,123,421$ & 0.576 & 0.197 & 0.424 & 0.227 \\
\hline 13 & $18,149,649$ & $12,658,083$ & 0.697 & $5,629,580$ & 0.310 & 0.303 & 0.690 & 0.387 \\
\hline 14 & $7,528,244$ & $12,437,099$ & 1.652 & $5,621,612$ & 0.747 & -0.652 & 0.253 & 0.905 \\
\hline 15 & $3,818,786$ & $12,408,187$ & 3.249 & $3,818,786$ & 1.000 & -2.249 & 0.000 & 2.249 \\
\hline 16 & $7,612,124$ & $12,211,371$ & 1.604 & $3,701,766$ & 0.486 & -0.604 & 0.514 & 1.118 \\
\hline
\end{tabular}




\begin{tabular}{|c|c|c|c|c|c|c|c|c|}
\hline 17 & $20,640,596$ & $11,968,117$ & 0.580 & $3,557,135$ & 0.172 & 0.420 & 0.828 & 0.407 \\
\hline 18 & $5,194,226$ & $11,949,628$ & 2.301 & $3,546,141$ & 0.683 & -1.301 & 0.317 & 1.618 \\
\hline 19 & $12,562,652$ & $11,937,367$ & 0.950 & $3,688,581$ & 0.294 & 0.050 & 0.706 & 0.657 \\
\hline 20 & $4,132,000$ & $11,788,790$ & 2.853 & $3,450,512$ & 0.835 & -1.853 & 0.165 & 2.018 \\
\hline 21 & $8,785,030$ & $11,714,861$ & 1.334 & $3,501,110$ & 0.399 & -0.334 & 0.601 & 0.935 \\
\hline 22 & $13,401,000$ & $11,538,314$ & 0.861 & $7,220,969$ & 0.539 & 0.139 & 0.461 & 0.322 \\
\hline 23 & $12,710,737$ & $11,464,101$ & 0.902 & $3,257,462$ & 0.256 & 0.098 & 0.744 & 0.646 \\
\hline 24 & $9,776,656$ & $11,306,885$ & 1.157 & $8,631,341$ & 0.883 & -0.157 & 0.117 & 0.274 \\
\hline 25 & $15,902,886$ & $11,140,890$ & 0.701 & $3,194,336$ & 0.201 & 0.299 & 0.799 & 0.500 \\
\hline 26 & $4,952,490$ & $10,967,868$ & 2.215 & $3,228,350$ & 0.652 & -1.215 & 0.348 & 1.563 \\
\hline 27 & $24,885,036$ & $10,892,153$ & 0.438 & $3,913,660$ & 0.157 & 0.562 & 0.843 & 0.280 \\
\hline 28 & $9,793,040$ & $10,809,247$ & 1.104 & $2,903,263$ & 0.296 & -0.104 & 0.704 & 0.807 \\
\hline 29 & $9,737,282$ & $10,797,887$ & 1.109 & $3,527,005$ & 0.362 & -0.109 & 0.638 & 0.747 \\
\hline 30 & $5,946,000$ & $10,719,911$ & 1.803 & $5,946,000$ & 1.000 & -0.803 & 0.000 & 0.803 \\
\hline 31 & $8,511,000$ & $10,662,251$ & 1.253 & $7,495,705$ & 0.881 & -0.253 & 0.119 & 0.372 \\
\hline 32 & $9,313,680$ & $10,618,940$ & 1.140 & $2,754,955$ & 0.296 & -0.140 & 0.704 & 0.844 \\
\hline 33 & $14,411,000$ & $10,616,441$ & 0.737 & $3,851,968$ & 0.267 & 0.263 & 0.733 & 0.469 \\
\hline 34 & $5,500,916$ & $10,463,810$ & 1.902 & $2,747,453$ & 0.499 & -0.902 & 0.501 & 1.403 \\
\hline 35 & $21,634,926$ & $10,463,597$ & 0.484 & $2,662,593$ & 0.123 & 0.516 & 0.877 & 0.361 \\
\hline 36 & $19,563,000$ & $10,381,616$ & 0.531 & $2,710,281$ & 0.139 & 0.469 & 0.861 & 0.392 \\
\hline 37 & $8,994,898$ & $10,362,428$ & 1.152 & $6,343,199$ & 0.705 & -0.152 & 0.295 & 0.447 \\
\hline 38 & $3,889,000$ & $10,310,102$ & 2.651 & $2,824,926$ & 0.726 & -1.651 & 0.274 & 1.925 \\
\hline 39 & $6,511,740$ & $10,284,927$ & 1.579 & $5,001,963$ & 0.768 & -0.579 & 0.232 & 0.811 \\
\hline 40 & $13,089,892$ & $10,282,908$ & 0.786 & $2,557,639$ & 0.195 & 0.214 & 0.805 & 0.590 \\
\hline 41 & $10,469,245$ & $10,280,165$ & 0.982 & $2,779,364$ & 0.265 & 0.018 & 0.735 & 0.716 \\
\hline 42 & $16,034,299$ & $10,209,197$ & 0.637 & $2,934,800$ & 0.183 & 0.363 & 0.817 & 0.454 \\
\hline 43 & $7,633,969$ & $10,183,707$ & 1.334 & $2,864,839$ & 0.375 & -0.334 & 0.625 & 0.959 \\
\hline 44 & $2,480,000$ & $10,156,496$ & 4.095 & $2,480,000$ & 1.000 & -3.095 & 0.000 & 3.095 \\
\hline 45 & $7,948,000$ & $10,137,685$ & 1.276 & $2,480,000$ & 0.312 & -0.276 & 0.688 & 0.963 \\
\hline 46 & $10,064,832$ & $10,087,049$ & 1.002 & $10,064,832$ & 1.000 & -0.002 & 0.000 & 0.002 \\
\hline 47 & $7,879,254$ & $10,064,871$ & 1.277 & $2,480,000$ & 0.315 & -0.277 & 0.685 & 0.963 \\
\hline 48 & $6,316,000$ & $10,064,379$ & 1.593 & $2,614,912$ & 0.414 & -0.593 & 0.586 & 1.179 \\
\hline 49 & $4,099,436$ & $10,041,447$ & 2.449 & $2,521,626$ & 0.615 & -1.449 & 0.385 & 1.834 \\
\hline 50 & $2,858,000$ & $10,034,710$ & 3.511 & $2,858,000$ & 1.000 & -2.511 & 0.000 & 2.511 \\
\hline 51 & $9,810,833$ & $10,030,581$ & 1.022 & $2,480,000$ & 0.253 & -0.022 & 0.747 & 0.770 \\
\hline 52 & $9,303,723$ & $10,028,328$ & 1.078 & $5,363,458$ & 0.576 & -0.078 & 0.424 & 0.501 \\
\hline 53 & $11,278,928$ & $10,019,606$ & 0.888 & $2,480,000$ & 0.220 & 0.112 & 0.780 & 0.668 \\
\hline 54 & $6,100,956$ & $10,004,779$ & 1.640 & $3,308,646$ & 0.542 & -0.640 & 0.458 & 1.098 \\
\hline 55 & $10,669,919$ & $9,972,809$ & 0.935 & $6,346,557$ & 0.595 & 0.065 & 0.405 & 0.340 \\
\hline Avg. & $10,794,016$ & $11,493,402$ & 1.368 & $4,728,704$ & 0.524 & -0.368 & 0.476 & 0.843 \\
\hline Min & $2,480,000$ & $9,972,809$ & 0.438 & $2,480,000$ & 0.123 & & & \\
\hline Max & $24,885,036$ & $15,984,851$ & 4.095 & $10,111,000$ & 1.000 & & & \\
\hline \multicolumn{9}{|c|}{ Medium } \\
\hline Avg. & 5316826.178 & 5316826 & 1.332 & 2061544 & 0.447 & -0.332 & 0.553 & 0.884 \\
\hline Min & 582780 & 3547984 & 0.352 & 582780 & 0.090 & & & \\
\hline $\operatorname{Max}$ & 12884000 & 8857807 & 7.285 & 6917795 & 1.000 & & & \\
\hline \multicolumn{9}{|l|}{ Small } \\
\hline Avg. & 2790773 & 2790773 & 1.178 & 1292518 & 0.501 & -0.178 & 0.499 & 0.677 \\
\hline Min & 567820 & 1423950 & 0.469 & 567820 & 0.153 & & & \\
\hline Max & 6269112 & 4579289 & 3.506 & 3872478 & 1.000 & & & \\
\hline
\end{tabular}

Table 4 also reveals the results of the DEA. The input targets are the benchmarks for CEO compensation when the company determinants of return on equity and total assets are valid. The DEA efficiency is the inputorientated technical efficiency. The efficiency estimate for Company 1 is 1.000 , implying this company is fully efficient. The result is that the actual CEO compensation equals the input target. Company 2 is inefficient (0.426) with the result that the input target is far less than the actual CEO compensation. In total, five, six and nine companies are fully efficient (1.000), with an average efficiency estimate of $0.524,0.447$ and 0.501 for large, medium and small companies, respectively. 
The last three columns of Table 4 exhibits the percentage that each company's CEO is over- or (under)paid. For LRA, the calculation is $(\mathrm{y}-\hat{\mathrm{y}}) / \mathrm{y}$, where Company 1 , which is efficient according to LRA, indicates that its CEO is underpaid by $58.1 \%$, relative to the other large companies, while the CEO of Company 2 is relatively overpaid by $23.0 \%$. For DEA, the calculation is ( $\mathrm{y}$ - input target)/y, where Company 1 that is fully technical efficient, indicates its CEO receives the correct compensation, while the CEO of Company 2 is overpaid by $57.4 \%$. The last column is merely the difference between the over- (under)paid percentages by LRA and DEA to indicate the difference between the two models' benchmarks. The average over- or (under)paid percentages are given at the bottom of Table 4. When using LRA, all three samples indicate that CEOs are on average actually underpaid, namely by $36.8 \%, 33.2 \%$ and $17.8 \%$ for the large, medium and small companies, respectively. When using DEA, all three samples indicate that CEOs are on average actually overpaid, namely by $47.6 \% 55.3 \%$ and $49.9 \%$ for large, medium and small companies, respectively.

The correlation coefficients between the LRA and DEA efficiencies are, $r=0.744,0.587$ and 0.689 for the efficiencies of large, medium and small companies, respectively. Furthermore, the correlation coefficients between the LRA and DEA benchmark are $r=0.879,0.862$ and 0.618 for large, medium and small companies, respectively. Although the two models show a strong association between these efficiencies and benchmarks, the (main) null hypothesis of the study is still to be tested, namely that there is no difference between the means of the LRA and DEA benchmarks. Therefore, to determine the difference between the two means for these dependent samples, the paired t-test was executed. The data are revealed in Table 5, where the t-stat and p-value refer to the upper tail, implying a one-sided upper-tailed test.

Table 5 t-test hypothesis test

\begin{tabular}{|c|c|c|c|}
\hline & Large & Medium & Small \\
\hline t Stat & 28.059 & 37.859 & 31.255 \\
\hline$P(T<=t)$ one-tail & $<0.001$ & $<0.001$ & $<0.001$ \\
\hline t Critical one-tail & 1.674 & 1.669 & 1.668 \\
\hline
\end{tabular}

Table 5 exhibits that the t-stats of all three groups of companies fall well above the lower limit indicated by the $t$ critical one-tail value. Therefore, $\mathrm{H}_{0}$ is rejected in favor of $\mathrm{H}_{1}$ (for all three samples), since the $\mathrm{t}$-stats fall above the upper limits of 1.674, 1.669 and 1.668 , respectively. Alternatively, the p-values $(<0.001)$ imply that there is overwhelming evidence that $\mathrm{H}_{0}$ should be rejected in favor of $\mathrm{H}_{1}$.

\section{SUMMARY AND CONCLUSION}

This paper is an empirical investigation of two alternative models to analyze CEO compensation with special reference to South Africa. The study follows a route of statistical modeling, i.e. that DEA is investigated as an alternative to the frequently used LRA to predict benchmark CEO compensation. The missing knowledge in the literature is that it is uncertain how the benchmark results of LRA differ from the results of DEA. The purpose of this study is to empirically compare the results of CEO compensation benchmarks set by LRA and DEA. To fulfill this purpose, an empirical investigation on South African listed companies was executed using a sample of 187 listed JSE companies. This resulted in category sizes of $n=55, n=64$ and $n=68$ for the large, medium and small companies, respectively. It was also hypothesized that the benchmark mean (average) of LRA ( $\hat{y}$ ) is significantly greater than the benchmark mean (average) of DEA (input targets).

For the LRA model, total CEO compensation is the dependent variable (y) with return on equity (as an accounting-based measurement of performance) and total assets (as measurement of company size) as the independent variables (x). The "expected" or "average" CEO compensation is calculated, as a benchmark, for each company and compared to the actual value of the CEO compensation. Furthermore, an efficiency estimate is calculated by dividing the expected CEO compensation into the actual CEO compensation. In the DEA model, total CEO compensation is the input variable and return on equity and total assets the two output variables. The inputorientated technical efficiency estimate is calculated to determine how efficient each company's CEO is to convert his/her compensation into the company determinants of return on equity and total assets. Furthermore, the input targets (benchmarks for CEO compensation) set by the DEA model are compared to the actual CEO compensation. 
The two models show a strong association between the efficiencies and the benchmarks, but the null hypothesis was overwhelmingly rejected in favor of the alternative hypothesis, that the difference between the means of the LRA and DEA benchmarks is significant. Although different variables in the models would provide different outcomes, this exploratory study indicates that the two alternative models provide extremely different views. This study found that, using the LRA model, CEOs are on average actually underpaid in monetary terms by $36.8 \%, 33.2 \%$ and $17.8 \%$ for the large, medium and small companies, respectively. In contrast, the results have shown that CEOs are on average actually overpaid in monetary terms by $47.6 \% 55.3 \%$ and $49.9 \%$ for large, medium and small companies, respectively. This implies that LRA, based on "averages", favors CEOs in comparison to the DEA model that is based on "best practices". Therefore, this study concludes that the frequently used model of LRA to analyze CEO compensation is probably a reason that contributes to excessive CEO compensation.

The practical implication is that LRA should not be used alone as a model to analyze CEO compensation, because using "averages" as a benchmark may contribute to the continuously increasing upwards spiral due to most company boards wanting their CEOs to be in the top half of the CEO's peer group. Using DEA simultaneously with LRA may provide more substance and a broader perspective to company board members into the setting of CEO compensation. This may limit excessive remuneration and decrease the gap between CEO remuneration and that of the average worker in order to alleviate the negative climate.

The value of the study is that this is the first effort to empirically compare CEO compensation benchmarks using two alternative models, namely LRA and DEA. Further research should be done, firstly where the role of different sectors is accommodated and secondly, to extend the DEA model to set benchmarks for individual input items such as salary, bonus, other short-term remuneration (e.g. pension fund contributions) and long-term remuneration (e.g. stock options), and thirdly, to include more variables that may explain changes in CEO compensation, e.g. experience and age of the CEO and market-based performance measures, and fourthly, to consider whether and how long-term schemes as part of CEO compensation should be included and finally, to take time lags into account.

\section{AUTHOR INFORMATION}

Professor Merwe Oberholzer is currently Professor in the School of Accounting Sciences at the North-West University (Private Bag X6001, North-West University, Potchefstroom, 2520, South Africa). He has taught extensively in the Chartered Accountancy and Chartered Management Accountancy programs. His academic research output includes approximately 40 peer-reviewed articles and conference presentations. His current research focuses on corporate resilience, social responsibility and DEA modeling. E-mail: Merwe.Oberholzer@nwu.ac.za (Corresponding author)

Marli Theunissen is currently an assistant cost accountant at VKB Agriculture Limited, an agricultural business whose core strategy is to add value to the agricultural producers in South Africa. She obtained both her BCom and BCom Honors in Management Accounting with distinction at the North-West University (South Africa) and studied as an exchange student for one semester at the Vrije University in Amsterdam (The Netherlands). She is currently researching the application of DEA on CEO remuneration in partial fulfillment of the requirements for her master's degree in Management Accounting. E-mail: Marlitheunissen@gmail.com

\section{REFERENCES}

1. Amble, B. (2006). "The knock-on effect of CEO pay". Management-issues: 1-2, September, $29^{\text {th }}$. Available, http://www.management-issues.com/2006/9/29/research/the-knock-oneffects-of-ceo-pay.asp. Accessed on January $23^{\text {rd }}, 2012$.

2. Anderson, T. (1996). "A data envelopment analysis (DEA) homepage". Available, www.emp.pdx.edu/dea/homedea.html. Accessed on February $15^{\text {th }}, 2010$.

3. Asaftei, G. (2008) "The contribution of product mix versus efficiency and technical efficiency change in US banking”. Journal of Banking \& Finance, 32:2336-2345. Available, www.sciencedirect.com. Accessed on November $21^{\text {th }}, 2011$. 
4. Avkiran, N.K. (1999). "An application reference for data envelopment analysis in branch banking: Helping the novice researcher". International Journal of Bank Marketing, 17(5):206-220.

5. Banks, G. (chair). (2009). Executive remuneration in Australia. Productivity Commission, Melbourne.

6. Barber, N., Ghiselli, R. and Deale, C. (2006). "Assessing the relationship of CEO compensation and company financial performance in the restaurant segment of the hospitality industry". Journal of Foodservice Business Research, 9(4):65-82.

7. Bernard, M.R. (2008). "The impacts of CEO turnover \& degree of internationalization on the accuracy of analyst forecasts”. International Business \& Economics Research Journal, 7(7):1-26.

8. Bradley, S. (2011). "Chief Executive Officer compensation and the effect on company performance in a South African context". MCom thesis, Rhodes University, Grahamstown.

9. Buys, P.W., Oberholzer, M. and Prinsloo, T. (2011). "Estimating scale efficiency of platinum-mining companies' environmental performance: A South African perspective". International Business \& Economics Research Journal, 10(12):11-22.

10. Chen, Y., Gregoriou, G.N. and Rouah, F.D. (2008). "Efficiency persistence of bank and thrift CEOs using data envelopment analysis". Computers \& Operational Research, 36:1554-1561. Available, www.elsevier.com/locate/cor. Accessed on March 21 $1^{\text {st }}, 2012$.

11. Coelli, T.J., Rao, D.S.P., O’Donnell, C.J. and Battese, G.E. (2005). An Introduction to Efficiency and Productivity Analysis. Springer, New York.

12. Cook, W.D. and Seinford, L.M. (2009). "Data envelopment analysis (DEA) - Thirty years on". European Journal of Operating Research, 192:1-17.

13. Cordeiro, J.J., Mukherjee, P. and Kent, D.D. (2006). "Non-parametric assessment of CEO compensation practices". Management Research News, 29(5):242-251.

14. Correia, C., Flynn, D., Uliana, E. and Wormald, M. (2011). Financial Management. Juta, Cape Town.

15. Dommisse, J. (2011). "Is die vergoeding van die uitvoerende hoofde van die 120 top-maatskappye van die Johannesburgse aandelebeurs (JSE) in verhouding tot hul omset, inkomste of wins voor rente en belasting geregverdig?" (Is the remuneration of chief executives of the 120 top-companies on the Johannesburg Stock Exchange (JSE) in relation to their turnover, income or profit before interest and taxes?) MCom mini-thesis, University of Stellenbosch.

16. Ellis, S.M. and Steyn, H.S. (2003). "Practical significance (effect size) versus or in combination with statistical significance (p-values)". (Research note) Management Dynamics, 12(4):51-53.

17. Ensor, L. (2010). "Gordhan warns of dangers in high CEO pay". Business day: 1-2, May, 12 $2^{\text {th }}$. Available, http://www.businessday.co.za/articles/Content.aspx?id=108643. Accessed on May $12^{\text {th }}, 2010$.

18. Financial Mail. (2008). "Executive pay - is intervention required?" Financial Mail: 1-5, August $2^{\text {nd }}$. Available, http://www.leader.co.za/printarticle.aspx?s=1\&f=1\&a=825. Accessed on April $6^{\mathrm{th}}, 2010$.

19. Finweek. (2012). “Investec's Koseff leads corporate gravy train". Finweek: 24-25, March $29^{\text {th }}$.

20. Hayes, R.M. and Schaefer, S. (2007). CEO pay and the lake Wobegon effect. University of Utah, Salt Lake City.

21. Hindery, L. (2008). "Executive pay - is intervention required?" Bloomberg Businessweek: 1-3, November $4^{\text {th }}$. Available, http://www.businessweek.com/print/managing/content/nov2008/ca2008114_493532.htm. Accessed on May $4^{\text {th }}, 2011$.

22. Joubert, N. (2011). “Top directors' salaries jump 23\%”. Fin24: 1-2, July $8^{\text {th }}$. Available, http://www.fin24.com/Economy/JSE-directors-salaries-up-23-20110708. Accessed on July 12 $2^{\text {th }}, 2011$.

23. Krugel, L. and Kruger, J. (2006). Remuneration of chief executive officers: An overview of JSE listed companies. Solidarity Research Institute.

24. Longman: Dictionary of contemporary English. (2004). Pearson Education, Essex.

25. Maree, K. (Editor). (2011). First steps in research. Van Schaik, Pretoria.

26. McGregor BFA. (2012). "Database”. Available, http://mcgregorbfa.co.za. Accessed on March 2 2012.

27. Nourayi, M.M. and Daroca, F.P. (2008). "CEO compensation, firm performance and operational characteristics". Managerial Finance, 34(8):562-584.

28. Ray. S.C. (2004). Data envelopment analysis: Theory and techniques for economics and operational research. Cambridge University Press, Cambridge.

29. SAPA. (2011). "Cosatu slams CEO pay hikes". Fin24: 1, July $11^{\text {th }}$. Available, http://www.fin24.com/Economy/Cosatu-slams-CEO-pay-hikes-20110711. Accessed on July 17 $7^{\text {th }}, 2011$. 
30. Setiawan, D. (2008). "An analysis of market reaction to CEO turnover announcement: The case in Indonesia”. International Business \& Economics Research Journal, 7(2):119-128.

31. Statistics South Africa. (2012). "Key indicators". Available, http://www.statssa.gov.za/. Accessed on March $9^{\text {th }}, 2012$.

32. Swanepoel, J.W.H., Swanepoel, C.J., Van Graan, F.C., Allison, J.S. and Santana, L. (2010). Elementary statistical methods. AndCorp, Potchefstroom.

33. Thanassoulis, E. (1993). "A comparison of regression analysis and data envelopment analysis as alternative methods for performance assessments". The Journal of the Operational Research Society. 44(11):11291144.

34. The Associated Press \& McClatchy Newspapers. (2009). “Goal of Obama's CEO pay cap: Make Wall St. Accountable". The Seattle Times: $1-3$, February $5^{\text {th }}$. Available, http://seattletimes.nwsource.com/html/politics/2008709424_pay05.html. Accessed on April 8 2010.

35. Theunissen, P. (2010). Is executive remuneration out of control? Computus.

36. Wade, J.B., O'Reilly, C.A. and Pollock, T.G. (2006). “Overpaid CEO's and underpaid managers: Fairness and executive compensation”. Organization Science, 17(5):527-544, Sep.

37. Wegner, T. (2007). Applied business statistics: Methods and Excel-based applications. Juta, Cape Town.

38. Zhu, J. 2004. Quantitative models for performance evaluation and benchmarking: Data envelopment Analysis with spreadsheets and DEA Excel Solver. Kluwer Academic Publishers, Massachusetts. 
NOTES 